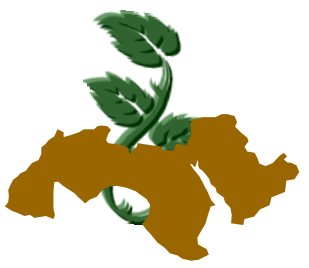

\title{
ANALYTIC STUDY OF SHORT FIBER CONTENT IN EGYPTIAN COTTON
}

\author{
Ebado', E.A. and Rokaya M. Hassan ${ }^{1}$ \\ 1- Cotton Research Institute, Agriculture Research Center, Giza, Egypt
}

Keywords: Cotton; Short fiber

\begin{abstract}
The present study was carried out to verify the variation of short fiber content (SFC) and its importance. The instruments and/ or methods used to measure short fiber include High Volume Instrument (HVI), Fibrograph 630 and Suter-Webb array.

Materials used in this study included the extra-long and long staple varieties with wide range of lint grades. The three measures of short fiber especially, Suter-Webb-SFC exhibited high variations for lint grades and low variations for cotton varieties. Suter-Webb short fiber shows higher values than the HVI and Fibrogragh short fiber. Results indicate that most of the fiber and yarn quality properties are strongly correlated with each of the three measures of short fiber content. Comparisons between the three measures indicate that they correlate well with each other. Highly significant regression model was developed to predict short fiber content from maturity percentage, fiber length, length uniformity and fiber strength. The closer normalized short fiber content (NSF) is to 1 (or $100 \%$ ), the higher the agreement between SFC and predicted short fiber content (PSF).
\end{abstract}

\section{INTRODUCTION}

One of the biggest concerns relative to the global marketing of cotton is the perception by international spinners that it contains excessive amounts of short fibers ( i. e. , fiber $<1 / 2$ in $(12.7$ $\mathrm{mm})$ ).

The presence of excess amounts of short fibers can cause significant problems for the spinner. These problems include excess waste, loss of yarn strength, increased end-down, and more yarn defects.
Behery (1993) described how short fibers behave during textile processing: during cotton spinning, the fiber strands are thinned or drafted by passing between pairs of drafting rolls that are spaced at distances that allow most fibers to pass through without bridging the gap between the rollers, which would result in breaking of the fibers. Short fibers are allowed to float between the drafting rollers where they can bunch up or thin out causing thick and/ or thin imperfections in the yarn with accompanying diminish of strength.

Over the years, several researchers have studied problems arising in cotton spinning resulting from the presence of short fibers.

Backe (1986) reported that short fiber showed a statistically significant influence on end-down. There was also a significant increase in Uster CV\% and classimate long thin places. Likewise, yarn strength, appearance index, and thick and thin places were all affected by an increase in short fibers at the $95 \%$ confidence level.

Bargeron (1986) studied the effects of short fibers on spinning performance by adding varying percentages of comber noils to raw cottons. Yarn strength diminish by more than $10 \%$, appearance grade decreased by more than $30 \%$ and irregularity $\%$ CV increased by more than $20 \%$.

Chanselme et al (1997) reported on the use of AFIS fiber data to study the effect of fiber properties (including short fibers) on yarn quality. Short fiber content correlated significantly with hairiness, yarn evenness, thin places, thick places and nep count. Similar results were obtained by Hequet (1999) in another study utilized also advanced fiber information system (AFIS) fiber data.

In regard to measure short fiber content, several methods can be used, and all of them essentially require some type of measurement of the distribution of total fiber length. The most fundamental, direct and tedious measure is the SuterWebb array method in which a comb-sorting tech- 
nique is used to segregate the fibers into length groups, each of which are weighed on an analytical balance (ASTM D: 1440, 2002). The AFIS instrument is also a direct measurement of fiber lengths, where the length of each fiber can be measured by a high speed electro/optic system as the instrument utilizes a mechanical opener to inject individual fibers into a rapid air stream.

There is some legitimate concern that the AFIS mechanical opener can cause some breakage, which would bias its length measurement (Cui et al 1997).

In the late 1980s, researchers began considering the possibilities of utilizing data from HVI (high volume instrument) to predict short fiber content as determined by the other more tedious methods.

Ramey and Beaton (1989) obtained their data from the crop quality survey of the 1984 and 1985 U.S. cotton crop using the Suter-Webb array method, the Peyer Almeter, the digital fibrograph, and the MCL (Motion control incorporated) HVI. The results showed negative simple correlations in the order of $-0.7<r<-0.6$ between short fiber content and the uniformity index. Additionally, correlations of approximately $r=-0.95$ were obtained when they employed a series of staple length standards.

Zeidman et al (1991) developed regression models for both SFN (short fiber by number) and SFW (short fiber by weight) using quality survey data from 1985, 1986 and 1987. They used modified Suter-Webb array distributions to determine short fiber content in terms of the HVI length parameters, UHM (upper-half mean, mean length and uniformity index. Multiple $\mathrm{R}^{2}$ values for FSN and FSW were 0.391 and 0.483 , respectively.

In the late 1990s, Zellwager Uster (now Uster Technologies) modified its HVI program to allow for calculation of the short fiber content based upon an algorithm that calculates a short fiber index (SFI) from the conventional $\mathrm{HVI}$ measures of length, strength and micronaire value.

Subsequently, the USDA-AMS Cotton Program developed an improved short fiber prediction equation based upon HVI length and uniformity index (Knowlton, 2001). Because the HVI length/ strength sample consists of a combed fiber bearded held at one end by a clamp with finite depth, most of the short fiber is hidden within the jaws of the clamp. For this reason, Thibodeaux et al (2008) pointed out that HVI-SFI was developed from regression-type studies using either SuterWebb or AFIS as reference methods.
To evaluate the differences between the various measures of short fiber content Cui et al (2003) reported a study including Suter-Webb, HVI and AFIS. Studies of the interrelationships between Suter-Webb, AFIS and HVI short fiber yielded correlation coefficients between 0.6 and 0.7 ; Some of the conclusions reached in that study were that real differences existed between the three methods and that a significant contributor to these differences was the general non-uniformity of the samples.

In this study we seek to validate and possibly improve upon the previously studies. Our emphasis is to study the relationships among the various measurements of short fiber and also their relationships to other fiber properties and end product. Finally, given that in general, the Suter-Webb array method is not available to those concerned with short fiber content. It is of interest to derive predictive models for Suter-Webb short fiber content that would use data obtained from $\mathrm{HVI}$ or another instrument.

\section{MATERIALS AND METHODS}

The materials used in this study are the six commercial varieties of Egyptian cottons which were grown in 2009 crop season. Three of these varieties belong to the extra- long staple category, i.e. Giza 92, Giza 88 and Giza 70, while the other three ones belong to the long staple class, i.e. Giza 86, Giza 80 and Giza 90. Four lint grades namely; Good/ Fully Good (G/FG), Good (G), Fully Good Fair/Good (FGF/G) and Fully Good Fair (FGF) of each variety were supplied from different regions.

From each lint grade, sub samples (6 replicates) each was drown to determine the raw fiber characteristics and yarn quality properties. High volume instrument (HVI- 900) according to ASTM (D: 4605-86) was used to determine fiber properties, i.e. maturity percentage (MT), Upper Half Mean (UHM), uniformity index (UI), fiber strength $(\mathrm{FS})$, Elongation (E), micronaire value (MIC), and short fiber index (HVI-SFI). In separate runs, used the fibroghraph 630 according to ASTM (D: 144767) to measure fiber length parameters including short fiber index (F-SFI) whereas, utilized the Suter-Webb array to measure short fiber content (SW-SFC) according to ASTM (D: 1444-005).

Yarn strength (YS) quoted is the product of lea strength in pound $x$ count using the Good Brand Lea Tester according to ASTM (D: 1568-68). 
Yarn appearance grade (YG) was determined as specified in the ASTM (D:2255-64). For a feasible statistics procedure, yarn appearance grades were converted into a numerical index as shown below :

$\begin{array}{cc}\text { Grade } & \text { Index } \\ \text { A\& above } & 130 \\ \mathrm{~B}+ & 120 \\ \mathrm{~B} & 110 \\ \mathrm{C}+ & 100 \\ \mathrm{C} & 90 \\ \mathrm{D}+ & 80 \\ \text { below D } & 70\end{array}$

All tests were conducted at the laboratories of the Cotton Research Institute (CRI), Agriculture Research center (ARC), Giza, Egypt.

Data obtained were computed using Minitab ${ }^{\text {TM }}$ 15 software (Minitab, Inc., State College, PA) for the analysis of variance. Pearson correlation coefficients among all possible traits and models of regression to evaluate the contribution to short fiber content .

\section{RESULTS AND DISCUSSION}

The results of this study will be dealt below under four categories; The first section discusses the importance of short fiber content. Variation in short fiber measurements, in the second section. The third, comparing the three methods of short fiber assessment. Finally, predictive models for short fiber content.

\section{1- The importance of short fiber content}

Here we are concerned with the relationship of short fiber content to other fiber properties and corresponding yarn properties.

The descriptive statistics of fiber properties are shown in Table (1). The data obtained from $\mathrm{HVI}$ showed wide ranges. Note that for fiber length (UHM), length uniformity index (UI) and micronaire value (MIC) each property's median and mean values are approximately the same indicating symmetric distributions of these values. This is not so in the case of fiber strength (FS), fiber elongation (E\%) and maturity percentage (MT) where the differences between the median and mean would indicate a skewed distribution, where FS and MT exhibits negative skewness and $\mathrm{E} \%$ is positively skewed.

Table 1. Descriptive statistics for HVI properties

\begin{tabular}{|ccccccc|}
\hline & $\begin{array}{c}\text { UHM } \\
\mathbf{m m}\end{array}$ & Ul\% & $\begin{array}{c}\text { FS } \\
\mathbf{g} / \text { tex }\end{array}$ & E\% & $\begin{array}{c}\text { MIC } \\
\text { unit }\end{array}$ & MT\% \\
\hline Mean & 32.23 & 84.7 & 40.4 & 7.0 & 4.01 & 0.89 \\
Median & 32.25 & 85 & 41.1 & 6.8 & 4.0 & 0.90 \\
Min & 26.80 & 80.4 & 29.2 & 6.2 & 3.3 & 0.80 \\
Max & 36.4 & 88.4 & 50 & 8.3 & 4.9 & 0.95 \\
SD & 2.62 & 2.20 & 6.00 & 0.6 & 0.38 & 0.032 \\
\hline
\end{tabular}

The descriptive statistics of yarn strength (YS) and yarn appearance grade (YG) are given in Table (2). The two characteristics ranged widely, on the other hand, the differences between the median and mean of their values would indicate a negatively skewed distributions.

Table 2. Descriptive statistics for yarn quality properties

\begin{tabular}{|ccc|}
\hline & YS & YG \\
\hline Mean & 2325 & 95 \\
Median & 2440 & 100 \\
Min & 1135 & 60 \\
Max & 3110 & 120 \\
SD & 506 & 17.4 \\
\hline
\end{tabular}

The relationships of individual short fiber measurements to fiber characteristics discussed in this study are examined in the correlation matrix in Table (3). The three measurements of short fibers are significant and highly significant to each of the fiber variables.

These correlations are approximately close in values, SW-SFC would ranked first, then HVI-SFI with slight weaker, and F-SFI later. It could be seen that the lower and opposite in sign correlations were those of fiber elongation $(E \%)$ to the three measurements of short fiber. 
Table 3. Correlation coefficients of short fiber measures with fiber quality properties

\begin{tabular}{|ccccccc|}
\hline & UHM & UI\% & FS & E\% & MIC & MT \\
\hline SW- & & & & & & \\
SFC & -0.604 & -0.767 & -0.613 & 0.443 & -0.735 & -0.819 \\
HVI- & & & & & & \\
SFI & -0.524 & -0.698 & -0.504 & 0.356 & -0.699 & -0.755 \\
F-SFI & -0.450 & -0.606 & -0.465 & 0.338 & -0.635 & -0.642 \\
\hline
\end{tabular}

The relationships of short fiber measurements to yarn strength (YS) and yarn appearance grade (YG) are examined in correlation matrix in Table (4). These correlations of the three measurements of short fiber to $Y S$ and YG are negative and highly significant, whereas, correlations to $Y G$ are higher than YS. This is due to the high association of short fibers with the yarn variables that affecting yarn appearance grade, i.e. thin and thick places and nep count. Generally, the strong pairwise correlations between the three measures of short fiber to the conjunction fiber properties and corresponding yarn properties suggest that short fiber content is an important determinant of spinning performance.

Table 4. Correlation coefficients of the three measures of short fiber with yarn quality properties

\begin{tabular}{|ccc|}
\hline & Y S & Y G \\
\hline SW-SFC & -0.674 & -0.891 \\
HVI-SFI & -0.586 & -0.877 \\
F-SFI & -0.552 & -0.819 \\
\hline
\end{tabular}

\section{2- Variation in short fiber content}

Specifications of the 144 observations pertaining to the six varieties (G.92, G88, G.70, G.86, G.80 and G.90) and four lint grades (G/FG, G,
FGF/G and FGF) for various characters of relevance to the study are shown in Table (5). Results depict wide differences among lint cotton grades for the three measures of short fibers. Also it could be seen that the increase in the value of short fibers is associated with a decrease in lint grades.

This association could be clearly seen in Figure (1). Also, illustrates the high variation in SWSFC than HVI-SFI and F-SFI.

Figure (2). reveals the poor differences for each measure of short fibers among extra-long cotton varieties. Whereas, long staple varieties exhibits high differences.

Either extra- long staple varieties namely G.92, G.88 and G.70 or long staple varieties (G.86, G.80 and G.90) are very much close with no apparent significance in each of short fiber measures. This for exception SW-SFC values of long staple varieties where the differences among the three varieties are high. Within the same cotton variety, high variation of short fiber content for the three measures could be clearly seen, especially of SWSFC. The same nominal grade for different varieties has different values of short fibers. Note that, values of SW-SFC for long staple varieties and lint grades are higher than extra-long staple varieties. Generally, SW-SFC exhibits values of short fibers higher than HVI-SFI and F-SFI.

\section{3- Comparing the three measures of short fibers}

Descriptive statistics for SW-SFC, HVI-SFI and F-SFI are shown in Table (6). Comparing the differences between mean and median values reveal that HVI short fibers are symmetrically distributed, whereas, SW-SFC and F-SFI are positively skewed. Suter-Webb short fibers exhibit wideness range more than $\mathrm{HVI-SFI}$ and $\mathrm{F}-\mathrm{SFI}$.

The correlation coefficients ( $r$-values) among the three measures are shown in Table (7). The association between the three measures is quite high. The strongest correlation is that of HVI-SFI to F-SFI ( $r=0.937)$. HVI short fiber exhibit high correlation coefficient to SW-SFC $(r=0.934)$, slight low correlation obvious for SW-SFC to F-SFI $(r=0.884)$. These results are in general agreement with those obtained by Cui et al (2003) and Knowlton (2001). 
Table 5. Average values $\%$ of the three measures of short fiber SW-SFC, HVI-SFI and F-SFI

\begin{tabular}{|c|c|c|c|c|c|c|c|c|c|c|}
\hline \multirow{2}{*}{$\begin{array}{c}\text { SF- } \\
\text { Measure }\end{array}$} & & \multicolumn{4}{|c|}{ Extra- Long staple varieties } & \multicolumn{4}{|c|}{ Long staple varieties } & \multirow{2}{*}{$\begin{array}{l}\text { Grand } \\
\text { mean }\end{array}$} \\
\hline & & G92 & G88 & G70 & mean & G86 & G80 & G90 & mean & \\
\hline \multirow{4}{*}{ SW-SFC } & $F G$ & 2.32 & 4.48 & 3.90 & 3.57 & 4.82 & 8.98 & 8.24 & 7.35 & 5.46 \\
\hline & G & 7.38 & 8.46 & 6.82 & 7.55 & 11.08 & 12.38 & 10.20 & 11.22 & 9.39 \\
\hline & FGF & 14.52 & 14.76 & 14.94 & 14.74 & 16.28 & 17.02 & 15.76 & 16.35 & 15.55 \\
\hline & GF & 20.86 & 21.42 & 21.86 & 21.38 & 21.26 & 24.94 & 23.04 & 23.08 & 22.23 \\
\hline $\begin{array}{l}\text { Variety } \\
\text { mean }\end{array}$ & & 11.27 & 12.28 & 11.88 & 11.81 & 13.36 & 15.83 & 14.31 & 14.50 & 13.16 \\
\hline \multirow{4}{*}{ HVI-SFI } & $F G$ & 5.94 & 5.98 & 5.74 & 5.89 & 5.90 & 6.26 & 6.38 & 6.18 & 6.03 \\
\hline & $\mathrm{G}$ & 6.66 & 6.60 & 6.16 & 6.47 & 7.10 & 7.04 & 6.64 & 6.93 & 6.70 \\
\hline & FGF & 7.50 & 7.58 & 7.00 & 7.36 & 8.26 & 7.66 & 7.50 & 7.81 & 7.58 \\
\hline & GF & 8.52 & 8.96 & 8.24 & 8.57 & 9.42 & 8.96 & 8.58 & 8.99 & 8.78 \\
\hline $\begin{array}{l}\text { Variety } \\
\text { mean }\end{array}$ & & 7.16 & 7.28 & 6.79 & 7.07 & 7.67 & 7.48 & 7.28 & 7.48 & 7.27 \\
\hline \multirow{4}{*}{ F-SFI } & $F G$ & 5.86 & 5.90 & 5.56 & 5.77 & 5.80 & 6.52 & 6.22 & 6.18 & 5.98 \\
\hline & $\mathrm{G}$ & 7.12 & 6.82 & 6.24 & 6.73 & 7.26 & 7.82 & 6.90 & 7.33 & 7.03 \\
\hline & FGF & 7.80 & 8.34 & 7.82 & 6.73 & 10.22 & 9.30 & 7.78 & 9.10 & 7.91 \\
\hline & GF & 9.68 & 10.18 & 9.88 & 9.91 & 13.04 & 11.74 & 9.12 & 11.30 & 10.61 \\
\hline $\begin{array}{l}\text { Variety } \\
\text { mean }\end{array}$ & & 7.62 & 7.81 & 7.38 & 7.29 & 9.08 & 8.85 & 7.51 & 8.48 & 7.88 \\
\hline
\end{tabular}

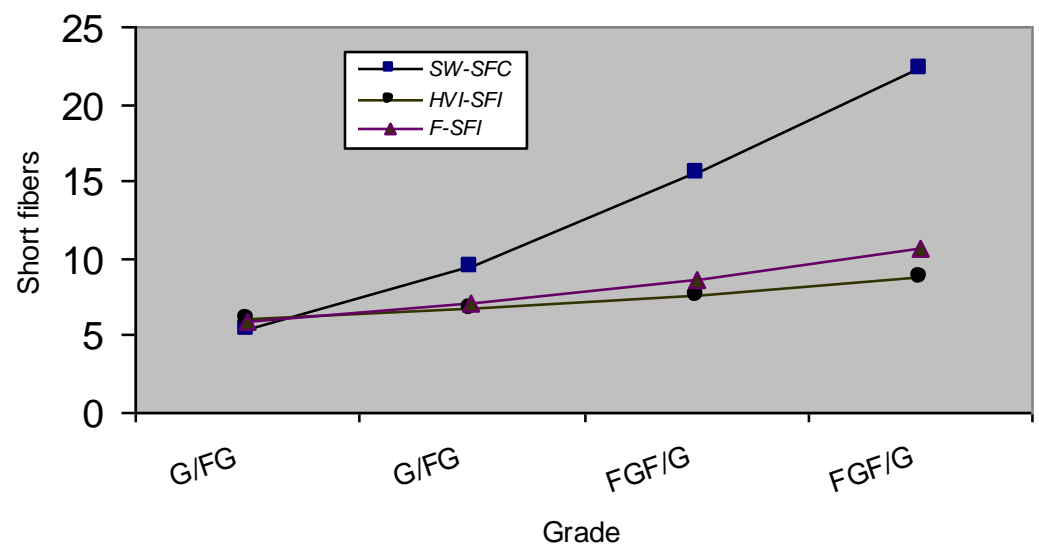

Figure 1. Relationship between short fibers and lint cotton grades 


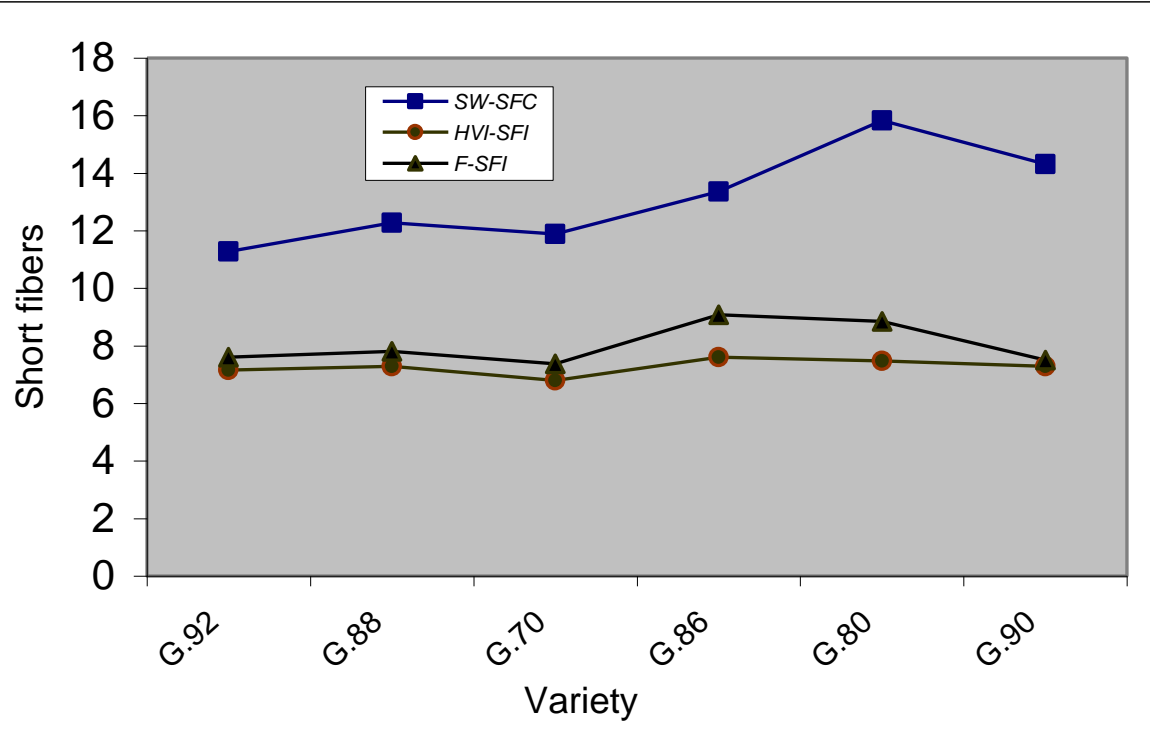

Figure 2. Relationship between short fibers and cotton varieties

Table 6. Descriptive statistics for the three measures of short fibers

\begin{tabular}{|cccc|}
\hline & SW-SFC & HVI-SFI & F-SFI \\
\hline Mean & 13.16 & 7.27 & 8.04 \\
Median & 12.95 & 7.15 & 7.60 \\
Min & 2.20 & 5.60 & 5.50 \\
Max & 26.10 & 10.0 & 14.80 \\
SD & 6.68 & 1.11 & 2.00 \\
\hline
\end{tabular}

Table 7. Correlation coefficients ( $r$ - values) among the three measures of short fiber (SW-SFC, HVI-SFI AND F-SFI

\begin{tabular}{|c|c|c|}
\hline & SW- SFC & HVI-SFI \\
\hline F-SFI & 0.884 & 0.937 \\
HVI-SFI & 0.934 & \\
\hline
\end{tabular}

These correlations are illustrated in matrix plot shown in Figure (3). They confirm the close relationship between the determinations of short fiber accomplished with $\mathrm{HVI}$ and Fibrograph compared with Suter-Webb array method. Therefore, either HVI-SFI or F-SFI (or others) would be considered a quite good indicator of short fiber content but not real. Generally, in this study we concentrate on HVI data to predict the short fiber content.

\section{4- Predictive model of SW-SFC}

The Suter-Webb array is traditionally considered the most accurate measure and accepted as the standard for short fiber content. However this method is extremely tedious, time consuming, requiring highly skilled technicians, and is not widely used.

On the other hand, the basic HVI properties are usually known for any cotton, and confirmed their high association with short fiber contenta And finally, because the HVI-SFI is not included as a standard output from the bale results.

Permanent suggestion is how standard classing data can be used to predict short fiber content. The stepwise forward regression with candidate predictors is shown in Table (8).

The highest contribution to variation in short fiber content exhibits of MT $\left(R^{2}=69.8\right)$. Non significant contribution comes from UHM, and low significance come from UI\% and FS. 


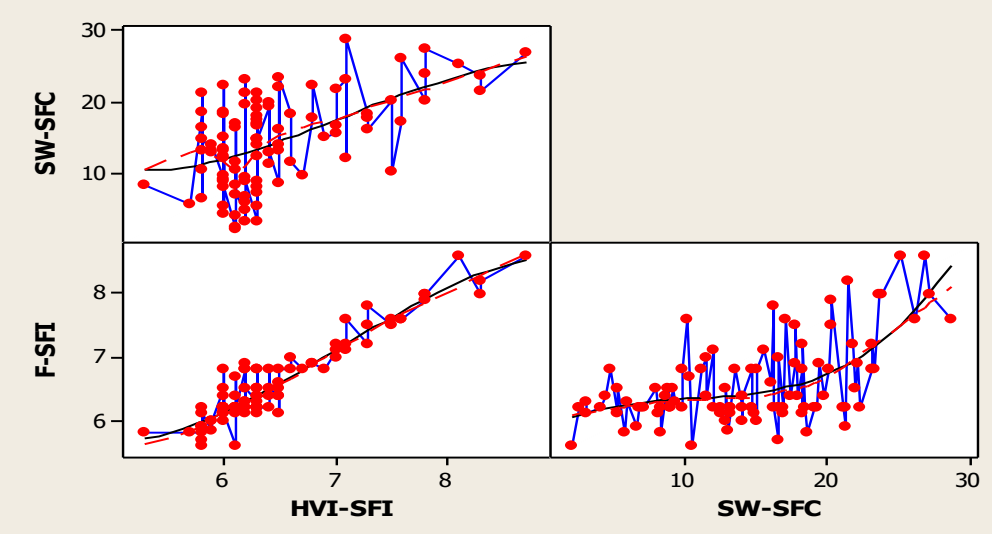

Figure 3. Matrix Plot of HVI-SFI;SW- SFC; F-SFI

Table 8. Contribution to variation in short fiber content

\begin{tabular}{|ccccc|}
\hline & $\mathbf{R}$ & $\mathbf{R}^{2} \%$ & Increase $\mathbf{R}^{2}$ & F-value \\
\hline MT & 0.835 & 69.8 & 69.8 & $240.9^{* *}$ \\
UHM & 0.838 & 70.3 & 0.50 & 4.08 \\
UI & 0.862 & 74.1 & 3.80 & $6.32^{*}$ \\
ST & 0.902 & 81.3 & 7.2 & $11.82^{*}$ \\
\hline
\end{tabular}

A good model for SFC is one with four predictors MT, UHM, UI\% and FS. Thus, the final regression equation with $\mathrm{R}^{2}=81.3 \%$ is: $\mathrm{SFC}=195.12-$ 125.8(MT) + 2.07 (UHM)-1.29(UI)-0.691(FS).

The multiple correlation coefficient approximately the unity $(R=0.902)$, this indicates that the model contains the appropriate entities.

The normalization of short fiber content (NSF) can be derived as a proportion of SFC to the predicted short fiber content (NSF=SFC/PSF). NSF indicates the degree of agreement between SFC and PSF. NSF has the potential for indicating a cotton sample has a normal amount of short fiber content or not. The closer NSF is to 1 (or $100 \%$ ) the higher the agreement. From grand means of all variables included in the regression equation, $P S F=12.70$, so $N S F=1.04$. This value indicates that the predicted short fiber content is in agreement with the measured short fiber content.

\section{REFERENCES}

ASTM, (2002). American Society for Testing and Materials. Designations: (2255-64), (1447-67), (1578-67), (4605-86) and (1444-05), Philadelphia 3, Pa, U.S.A.

Backe, E.E. (1986). Effect of short fiber content on plant performance and quality. Textile Res. J., 56 (21): 112-115.

Bargeron, J.D. (1986). Relationship between cotton length uniformity to yarn quality. Proceedings of the National Cotton Textile Conference, Myrtle Beach, SC. 6-8 November.

Behery, H. (1993). Short fiber content and uniformity index in cotton. International Cotton Advisory Committee. Review Articles on Cotton Product on Research. No. 4. CAB International, Wallingford, Oxon, UK.

Chanselme, J.; E. Hequet and R. Frydrh. (1997). Relationship between AFIS fiber characters and yarn evenness and imperfections. In: Proc. Beltwide Cotton Conf. pp. 512-516. New Orleans L A. 7-10 Jan 1997 Natl. Cotton Counc., Am., Memphis, TN.

Cui, X.; T. Calamari; K.Q. Robert and R. Krowicki. (1997). An investigation of cotton fiber lengths measured by HVI and AFIS.. In: Proc. Tenth EFS System Res. Forum, Raleigh NC, pp. 115-123. 6-7 Nov. 1997. Cotton Inc., Cary, NC. 
Cui, X.; T. Calamari; K.Q. Robert; J.B. Price and M.D. Watson. (2003). Measuring the short fiber content of cotton. Textile Res. J. 73 (10): 891895.

Hequet, E. (1999). Application of the AFLS multidata. In: Proc. Beltwide Cotton Conf. Orlando, pp. 666-670. FL. 3-7 Jan. 2000. Natl. Cotton Counc. Am Memphis, TN.

Knowlton, J.L. (2001). HVI short fiber measurements. In: Proc. Beltwide Cotton Conf. pp. 1245-1247. Anaheim, CA. 9-15 Jan. 2001. Natl. Cotton Counc. Am., Memphis, TN.
Ramey Jr., H.H. and P.G. Beaton. (1989). Relationships between short fiber content and fiber length uniformity. Tex. Res. Jour. 59(2): 101108.

Thibodeaux, D.; H. Senter; J.L. Knowlton; D. McAlister and X. Cui. (2008). A Comparison of Methods for Measuring the Short Fiber Content. Cotton Sci. J. 12: 298-305.

Zeidman, M.L.; S.K. Batra and P.E. Sasser. (1991). Determining short fiber content in cotton. Part II. Measures of SFC from HVI datastatistical models. Textile Res. J. 61(2): 106113. 